\title{
DISSERTAÇÕES E TESES EM EDUCAÇÃO FÍSICA: UMA INVESTIGAÇÃO SOBRE ABORDAGENS METODOLÓGICAS
}

\author{
DISSERTATIONS AND THESES IN PHYSICAL EDUCATION: AN INVESTIGATION \\ CONCERNED METHODOLOGICAL APPROACHES
}

\author{
DISERTACIONES Y TESIS EN EDUCACIÓN FÍSICA: UNA INVESTIGACIÓN \\ SOBRE LOS ENFOQUES METODOLÓGICOS
}

\author{
Pedro Henrique Zubcich Caiado de Castro*, Alan Camargo Silva*, \\ Sílvia Maria Agatti Lüdorf*
}

Palavras chave:
Produção científica.
Programas de
pós-graduação.
Educação Física.
Atividades científicas
e tecnológicas.

e tecnológicas.

\begin{abstract}
Resumo: 0 objetivo deste estudo foi analisar a produção científica em Educação Física de dissertações e teses de programas de pós-graduação stricto sensu, no período de 2001 a 2010, com enfoque em suas abordagens metodológicas. Os PPGEF selecionados foram: USP, UNESP, UFRGS, UNICAMP e UGF. A análise dos dados pautou-se na abordagem metodológica proposta por Gaya (2008). Os resultados apontaram predominância da abordagem nomotética, seguida da interpretativa e ausência da intervenção social. Conclui-se, com base em Bourdieu, que as regras do jogo científico têm influenciado a orientação metodológica da produção de conhecimento da área, o que pode repercutir na reprodução de modos hegemônicos de ciência no campo.
\end{abstract}

Keywords:

Scientific production.

Postgraduate

programs.

Physical Education.

Scientific and technical activities.

Palabras clave: Producción científica. Programas de posgrado. Educación Física. Actividades científicas y tecnológicas.
Abstract: The aim of this study was to analyze scientific production in Physical Education from theses and dissertations of post graduation programs, since 2001 to 2010, focusing on their methodological approaches. The Physical Education's post graduation programs selected were: USP, UNESP, UFRGS, UNICAMP and UGF. The data analysis was based on the methodological approach proposed by Gaya (2008). The results points the nomothetic approach's predominance, followed by interpretive and absence of social intervention. To conclude, based on Bourdieu, the rules of the scientific game have been influencing the methodological orientation of the production of knowledge in the area, which may reverberate on the reproduction of hegemonic ways of Science in the field.

Resumen: El objetivo fue analizar la producción científica en Educación Física desde tesis y disertaciones de programas de posgrado (maestría y doctorado), entre 2001 y 2010, concentrándose em sus enfoques metodológicos. Los programas de posgrado em Educación Física selecionados fueron: USP, UNESP, UFRGS, UNICAMP y UGF. EI análisis de datos se basó en el enfoque metodológico propuesto por Gaya (2008). Los resultados apuntaron predominancia del enfoque nomotético, seguido de lo interpretativo y ausencia de la intervención social. Se concluye, con base en Bourdieu, que las reglas del juego científico han influenciado la orientación metodológica de la producción de conocimiento del área, lo que puede repercutir en la reproducción de modos hegemónicos de ciencia en el campo.
*Universidade Federal do Rio de Janeiro. Rio de Janeiro, RJ, Brasil. E-mail: zubufrj@ hotmail.com; alan10@zipmail.com.br; sagatti.rlk@terra.com.br

Recebido em: 01-05-2018 Aprovado em: 23-02-2019 Publicado em: 24-05-2019

DOI: https://doi.org/10.22456/1982-8918.82495 (c) (i) () Licence 


\section{INTRODUÇÃO}

A década de 1990, a partir de políticas públicas que objetivaram o desenvolvimento científico dos mais diversos domínios do conhecimento no Brasil, constituiu-se em importante período para o desenvolvimento da Educação Física (EF) como campo acadêmico em busca de sua legitimação científica (DACOSTA; DUARTE, 2003; LOVISOLO, 2003). As múltiplas interfaces teóricas que a área possui com as Ciências Humanas e Sociais, Ciências Biológicas e as Ciências Naturais constituem alvo de permanente debate acerca dos pressupostos que fundamentam o campo científico da EF (LUDORF, 2002; CENÁRIOS..., 2015).

Nesta perspectiva, os PPGEF constituíram-se como locus propício para tal discussão (DACOSTA; DUARTE, 2003). Isto ocorreu, pois as políticas públicas de fomento à pesquisa e educação no ensino superior, no Brasil, definiram como principal responsabilidade dos programas de pós-graduação stricto sensu a atividade da pesquisa científica e produção de conhecimento (DACOSTA; DUARTE, 2003; LOVISOLO, 2003).

Atualmente, a Plataforma Sucupira da CAPES ${ }^{1}$ revela o número de 37 programas de pós-graduação stricto sensu - mestrado e doutorado acadêmicos - alocados na área básica da EF. Este quantitativo é expressivo, tendo em vista o recrudescimento destes programas desde a década de 1990, quando se registravam nove programas de pós-graduação.

Ante a importância do debate epistemológico que se instaura na área e o substancial aumento do número de programas, é tarefa fundamental investigar o conhecimento científico gerado neste âmbito. Minayo (1994) afirma que a pesquisa constitui "[...] uma atividade de aproximação sucessiva da realidade que nunca se esgota, fazendo uma combinação particular entre teoria e dados." (p. 23). A autora avança ao argumentar que a investigação científica sofre as limitações e contradições mais amplas do campo científico e dos aspectos socioculturais de cada época. Assim, é crucial o exercício de analisar as pesquisas que vêm sendo produzidas em EF visto que, espera-se, reflitam de certo modo as discussões empreendidas no âmbito acadêmico (LÜDORF, 2002).

No intuito de realizar tal empreendimento investigativo, a sociologia do conhecimento na perspectiva de Bourdieu (1983a, 1983b, 1984, 2004) fornece substratos importantes para compreensão das relações entre a pesquisa científica e a EF. Entende-se a EF como campo científico, uma vez que há instituídas relações objetivas entre agentes/ pesquisadores, tais como aquelas evidenciadas em entidades científicas, no debate intelectual, em congressos, na produção de livros, artigos, organização de períodos científicos e, também, na já consolidada existência de PPGEF. Ressalta-se também que este espaço de relações objetivas - o campo científico da EF - legitima-se, ainda, pela instituição de entidades específicas para a gestão de políticas públicas de fomento à ciência no país, principalmente, a CAPES e o CNPq² .

A teoria do campo científico de Pierre Bourdieu já foi alvo de outros estudos cujo escopo era compreender as relações que constituem, mantém e modificam o campo da EF (LAZZAROTTI FILHO et al., 2012; LAZZAROTTI FILHO; SILVA; MASCARENHAS, 2014, CASTRO et al., 2017, LÜDORF; CASTRO, 2017). Cabe pontuar as contribuições dos trabalhos citados ao identificarem que as preferências temáticas e metodológicas, encontradas no campo,

1 Plataforma alocada no sítio da Coordenação de Aperfeiçoamento de Pessoal de Nível Superior (CAPES). Mais informações em: https:// sucupira.capes.gov.br/. Acesso em: 25 fev. 2018.

2 Conselho Nacional de Desenvolvimento Científico e Tecnológico. Disponível em: http://cnpq.brl. Acesso em: 25 de fevereiro de 2018. 
são forjadas por disputas de prestígio e acúmulo de capital científico por pesquisadores das diferentes subáreas que compõem a EF.

Para além destas, ressaltam-se, ainda, que outras contribuições têm apresentado em seu bojo argumentativo a discussão sobre as interações entre pesquisa e regras de produção científica, pós-graduação e EF (SILVA, 1990, 1997; BETTI et al., 2004; LÜDORF, 2002; MANOEL; CARVALHO, 2011). Não obstante, a lacuna de estudos que visam a investigação da produção intelectual derivada de PPGEF, no que tange a dissertações e teses, no recorte temporal que compreende a primeira década do novo milênio, momento de crescimento destes programas, permanece e carece ser alvo de investigações.

Castro et al. (2017), em um primeiro momento, debruçaram-se sobre a discussão em torno dos enfoques temáticos presentes nas dissertações e teses. Este artigo, entretanto, visa centrar o foco de análise nas abordagens metodológicas, intimamente relacionadas com as subáreas da EF (MANOEL; CARVALHO, 2011), mas que necessitam ser perscrutadas em virtude de oferecerem potencial analítico singular para a compreensão das nuances do campo científico.

Diante do exposto, o objetivo deste estudo foi analisar a produção científica da EF, com enfoque nas abordagens metodológicas presentes em dissertações e teses de PPGEF, no período 2001-2010 3 .

\section{PROCEDIMENTOS METODOLÓGICOS}

A primeira década do novo milênio foi escolhida como recorte analítico neste estudo porque demonstra o vigor das transformações no campo da EF, seja pelo recrudescimento do número de PPG (ROSA; LETA, 2011) seja pelos embates sobre produtividade e impactos para a área (KOKUBUN, 2003, 2004; BETTI et al., 2004).

Assim, a seleção dos PPGEF baseou-se na premissa de que deveriam oferecer os cursos de mestrado e doutorado a partir do ano de 2001 e estivessem ativos até, pelo menos, 0 ano de 2010. Desta forma, pretendeu-se fornecer um panorama mais amplo sobre o campo.

Aplicado o critério, foram selecionados cinco PPGEF ${ }^{4}$ das seguintes instituições: Universidade de São Paulo (USP), Universidade Gama Filho (UGF), Universidade Estadual de Campinas (UNICAMP), Universidade Federal do Rio Grande do Sul (UFRGS) e Universidade Estadual Paulista (UNESP);

Para o levantamento e análise das dissertações e teses, foram acessados os bancos de teses online destes PPGEF e, também, o Banco de Teses ${ }^{5}$ da CAPES. Adicionalmente, em decorrência de algumas discrepâncias detectadas, solicitou-se aos coordenadores as listagens de defesa de dissertações e teses dos PPGEF investigados.

Os dados principais (título, autor, orientador, resumo e link do trabalho) foram sistematizados em planilhas, por universidade e nível (mestrado ou doutorado). Os PPGEF geraram o total de 1398 trabalhos, sendo 1086 dissertações de mestrado e 312 teses de doutorado.

3 O presente artigo deriva de dissertação defendida no PPGEF da Universidade Federal do Rio de Janeiro. Um resumo foi apresentado no XIX CONBRACE no ano de 2015.

4 O curso de doutorado dos PPGEF UFRGS e UNESP possuem a primeira tese defendida (até onde foi possível verificar), respectivamente, nos anos 2003 e 2004

5 Mais Informações em: http://bancodeteses.capes.gov.brl . Acesso em: 25 de fevereiro de 2018. 
Cabe destacar, para os fins desta investigação, a noção de Bourdieu (2011) sobre a indissociabilidade entre a construção teórica de uma pesquisa e os procedimentos metodológicos por ela adotados. Dito de outra forma, o encaminhamento metodológico de uma dissertação ou tese não expõem apenas os passos que o pesquisador seguiu para obter determinado resultado, mas, também, a concepção teórico-epistemológica que o alicerça e, em consequência, aspectos como sua concepção de ciência e relação pesquisador-pesquisado.

A categorização dos trabalhos foi realizada primordialmente a partir da leitura dos resumos das dissertações e teses. Entretanto, não raro, realizou-se acesso ao documento na íntegra, em especial, na ausência de insumos necessários apresentados pelo resumo para que a análise proposta por este estudo fosse contemplada.

O tratamento dos dados foi realizado mediante à Análise de Conteúdo Temático (TURATO, 2003), descrita como o processo de categorização dos trabalhos feito a partir de expressões textuais comuns, neste caso, que revelassem semelhanças quanto à concepção metodológica. Assim, os instrumentos metodológicos das dissertações e teses investigadas foram os principais substratos de análise desta pesquisa, pautados pela indissociável contextualização com o objetivo e o referencial teórico utilizados na investigação.-

No sentido de agrupar os estudos em eixos comuns que permitissem a melhor visualização das abordagens metodológicas da área, utilizou-se a definição sobre concepções de investigações científicas, em EF, adaptadas da proposta de Gaya (2008):-

a) Nomotética: estudos de caráter quantitativo, amparados na objetividade e imparcialidade do pesquisador, correlatos aos modelos de investigação científica das ciências físicas e naturais. Para Gaya (2008), "claramente se configuram como predominantemente nomotéticas as investigações da área biológica, tais como a fisiologia, a cineantropometria, a biomecânica, etc."

b) Interpretativa: abordagem metodológica utilizada pelas investigações centradas "na compreensão e na valoração das interpretações do indivíduo sobre a realidade" (GAYA 2008, p. 55). Os estudos são predominantemente de caráter qualitativo, com aportes das ciências humanas e sociais e baseados nos significados e intenções, ou seja, nos aspectos subjetivos das ações humanas.

c) Intervenção social: investigações realizadas com o intuito de levantar informações para fundamentar decisões que incidam em nível político. Nesta abordagem, as estratégias metodológicas podem apresentar características das duas concepções anteriores, desde que estejam subordinadas ao objetivo de mudança do contexto social analisado.

d) Outras: trabalhos que não puderam ser classificados devido à ambiguidade metodológica.

Adicionalmente, no que tange aos possíveis trabalhos alocados na categoria intervenção social, adotou-se como premissa a necessidade de que estes revelassem o comprometimento explícito - seja no objetivo de pesquisa, seja nos procedimentos metodológicos - com a intervenção, mobilização e transformação do contexto político-social dos sujeitos da pesquisa em análise. Portanto, não foram consideradas nesta categoria dissertações ou teses - ainda que numa perspectiva crítica do contexto investigado - que focalizavam estritamente algum nível de interpretação da realidade, mas não de evidente ensejo de transformação da mesma como parte da pesquisa. 


\section{RESULTADOS E DISCUSSÃO}

Inicialmente, os resultados serão apresentados em um panorama geral. Em seguida, serão destrinchados aspectos referentes às peculiaridades de cada PPGEF, bem como possíveis interpretações.

\section{DISSERTAÇÕES E TESES EM EF: O PANORAMA DE UMA DÉCADA}

O quadro 1 apresenta as abordagens metodológicas presentes nos PPGEF analisados, tanto no nível do mestrado (dissertações) quanto no doutorado (teses).

Quadro 1 - Abordagens metodológicas.

\begin{tabular}{|c|c|c|c|c|c|c|c|c|c|c|}
\hline & \multicolumn{2}{|c|}{ Nomotética } & \multicolumn{2}{c|}{ Interpretativa } & \multicolumn{2}{c|}{$\begin{array}{c}\text { Intervenção } \\
\text { Social }\end{array}$} & \multicolumn{2}{c|}{ Outras } & \multicolumn{2}{|c|}{ Total } \\
\hline PPGEF/Nível & M & D & M & D & M & D & M & D & M & D \\
\hline USP & $\begin{array}{c}78,2 \% \\
(161)\end{array}$ & $\begin{array}{c}93,2 \% \\
(55)\end{array}$ & $\begin{array}{c}20,8 \% \\
(43)\end{array}$ & $\begin{array}{c}3,4 \% \\
(2)\end{array}$ & 0 & 0 & $\begin{array}{c}1 \% \\
(2)\end{array}$ & $\begin{array}{c}3,4 \% \\
(2)\end{array}$ & $\begin{array}{c}100 \% \\
(206)\end{array}$ & $\begin{array}{c}100 \% \\
(59)\end{array}$ \\
\hline UGF & $\begin{array}{c}29,7 \% \\
(49)\end{array}$ & $\begin{array}{c}27,7 \% \\
(18)\end{array}$ & $\begin{array}{c}68,5 \% \\
(113)\end{array}$ & $\begin{array}{c}70,8 \% \\
(46)\end{array}$ & 0 & 0 & $\begin{array}{c}1,8 \% \\
(3)\end{array}$ & $\begin{array}{c}1,5 \% \\
(1)\end{array}$ & $\begin{array}{c}100 \% \\
(165)\end{array}$ & $\begin{array}{c}100 \% \\
(65)\end{array}$ \\
\hline UNESP & $\begin{array}{c}63,1 \% \\
(176)\end{array}$ & $\begin{array}{c}97,9 \% \\
(46)\end{array}$ & $\begin{array}{c}35,8 \% \\
(100)\end{array}$ & $\begin{array}{c}2,1 \% \\
(1)\end{array}$ & 0 & 0 & $\begin{array}{c}1,1 \% \\
(3)\end{array}$ & 0 & $\begin{array}{c}100 \% \\
(279)\end{array}$ & $\begin{array}{c}100 \% \\
(47)\end{array}$ \\
\hline UFRGS & $\begin{array}{c}66,2 \% \\
(143)\end{array}$ & $\begin{array}{c}69,2 \% \\
(27)\end{array}$ & $\begin{array}{c}32,4 \% \\
(70)\end{array}$ & $\begin{array}{c}25,7 \% \\
(10)\end{array}$ & 0 & 0 & $\begin{array}{c}1,4 \% \\
(3)\end{array}$ & $\begin{array}{c}5,1 \% \\
(2)\end{array}$ & $\begin{array}{c}100 \% \\
(216)\end{array}$ & $\begin{array}{c}100 \% \\
(39)\end{array}$ \\
\hline UNICAMP & $\begin{array}{c}44,6 \% \\
(98)\end{array}$ & $\begin{array}{c}30,4 \% \\
(31)\end{array}$ & $\begin{array}{c}51,8 \% \\
(114)\end{array}$ & $\begin{array}{c}66,7 \% \\
(68)\end{array}$ & 0 & 0 & $\begin{array}{c}3,6 \% \\
(8)\end{array}$ & $\begin{array}{c}2,9 \% \\
(3)\end{array}$ & $\begin{array}{c}100 \% \\
(220)\end{array}$ & $\begin{array}{c}100 \% \\
(102)\end{array}$ \\
\hline TOTAL & $\begin{array}{c}57,7 \% \\
(627)\end{array}$ & $\begin{array}{c}56,7 \% \\
(177)\end{array}$ & $\begin{array}{c}40,5 \% \\
(440)\end{array}$ & $\begin{array}{c}40,7 \% \\
(127)\end{array}$ & 0 & 0 & $\begin{array}{c}1,8 \% \\
(19)\end{array}$ & $\begin{array}{c}2,6 \% \\
(8)\end{array}$ & $\begin{array}{c}100 \% \\
(1086)\end{array}$ & $\begin{array}{c}100 \% \\
(312)\end{array}$ \\
\hline
\end{tabular}

Legenda: Número absoluto e percentual de dissertações e teses por PPGEF e abordagem metodológica, no período de 2001 a 2010. Fonte: Dados originais da pesquisa.

Os resultados apontam superioridade de dissertações e teses cuja abordagem metodológica pode ser classificada como nomotética. No que tange ao doutorado, principalmente nos PPGEF USP e UNESP, a abordagem nomotética está presente na quase totalidade das teses.

Gomes (2005) e Vanni (2008) são exemplos de trabalhos caracterizados pelos procedimentos metodológicos na perspectiva nomotética, pois utilizaram métodos de comparação de treinamento aeróbico e de força, com base em mensurações de insulina e/ou composição corporal, para atingir os objetivos propostos.

Em seguida, situa-se a abordagem metodológica interpretativa, com aproximadamente 40\% das dissertações e teses investigadas. Mais recorrente nos PPGEF UNICAMP e UGF, é praticamente inexpressiva em nível de doutorado nos PPGEF USP e UNESP. No PPGEF UFRGS, não constitui a terça parte do total de teses defendidas.

Machado (2006) e Oliveira (2010) são exemplos de investigação sob a perspectiva metodológica interpretativa ao utilizarem procedimentos como a análise documental, entrevistas semiestruturadas e observação de campo, típicos da perspectiva histórica-analítica ou antropológica. 
Quanto à abordagem metodológica intervenção social, não foi detectado exemplo nas dissertações e teses dos PPGEF analisados. Cabe pontuar que a proposta de mudança política do contexto social investigado é condição elementar para este tipo de pesquisa. Nesse sentido, não bastaria que o pesquisador participasse ou interagisse com os sujeitos de pesquisa, mas era necessário se configurar a finalidade de intervenção social no contexto investigado.

Foram alocados na categoria outras, os trabalhos que geraram ambiguidade quanto à categorização. Conceição (2008), por exemplo, embora utilize-se de instrumentos, em sua maioria, caros à perspectiva nomotética, mescla procedimentos também presentes na abordagem interpretativa, ao transitar entre questionários de variação espectral e uso de relatos de atletas. Este achado se coaduna com o alerta de Gaya (2008) de que cada uma das abordagens não se manifesta necessariamente de forma isolada ou excludente em relação às outras.

Os resultados aproximam-se, portanto, de Silva (1990), ao analisar as dissertações de mestrado dos PPGEF da USP, UFRJ e, Universidade Federal de Santa Maria (UFSM), desde a criação dos cursos até 1987. Na sequência, Silva (1997) avaliou os PPGEF da UNICAMP, UFRGS e Universidade Federal de Minas Gerais (UFMG) de 1988 até 1994, e com relação às dissertações, contabilizou: 66,22\% empírico-analíticas; $21,62 \%$ fenomenológicohermenêuticas; e 12\% crítico-dialéticas.

Corroboram, também, os dados analisados por Lüdorf (2002), a partir de resumos das dissertações e teses referentes aos programas de pós-graduação da área, período de 1990 até 1997, quais sejam: 56,5\% empírico-analíticas; 42\% fenomenológico-hermenêuticas; e 1,5\% crítico-dialéticas.

Embora as classificações ${ }^{6}$ utilizadas por estas duas autoras não sejam as mesmas do presente estudo, é possível considerar o mesmo vínculo entre as Ciências Naturais e as abordagens empírico-analíticas e nomotética, principalmente no que tange à tradição de quantificar e mensurar o objeto de estudo. Portanto, ao somarmos o presente trabalho à Silva (1990, 1997) e Lüdorf (2002), afirma-se a superioridade, nestes trinta anos - 1980 a 2010 -, representados no recorte temporal destes estudos, de uma concepção de EF voltada ao estudo quantitativo.

Considerando-se que a abordagem fenomenológico-hermenêutica utilizada por Lüdorf (2002) guarda similaridades à interpretativa (GAYA, 2008), é possível verificar que a proporcionalidade se manteve nas décadas analisadas. Caracteriza-se então a centralidade, dentro dos resultados encontrados, das abordagens metodológicas nomotética e interpretativa. De certa forma, esta tendência também foi detectada por Lazzarotti Filho et al. (2012) e Lazzarotti Filho, Silva e Mascarenhas (2014) ao terem observado a polarização entre dissertações e teses que possuem métodos e instrumentos de pesquisa próprios das Ciências da Natureza ou das Ciências Humanas e Sociais.

A figura 1 auxilia na compreensão da evolução de dissertações e teses vinculadas às diferentes abordagens metodológicas:

6 Imperativo ressaltar que o esforço argumentativo dá-se no sentido de dialogar com resultados de diferentes estudos. Portanto, não se está sugerindo que as concepções teórico-epistemológicas que sustentam as distintas categorias são as mesmas, mas que, por outro lado, seus pontos de convergência permitem constituir um panorama mais amplo e robustecer a análise dos resultados do presente artigo. 
Figura 1 - Evolução das abordagens metodológicas por ano.

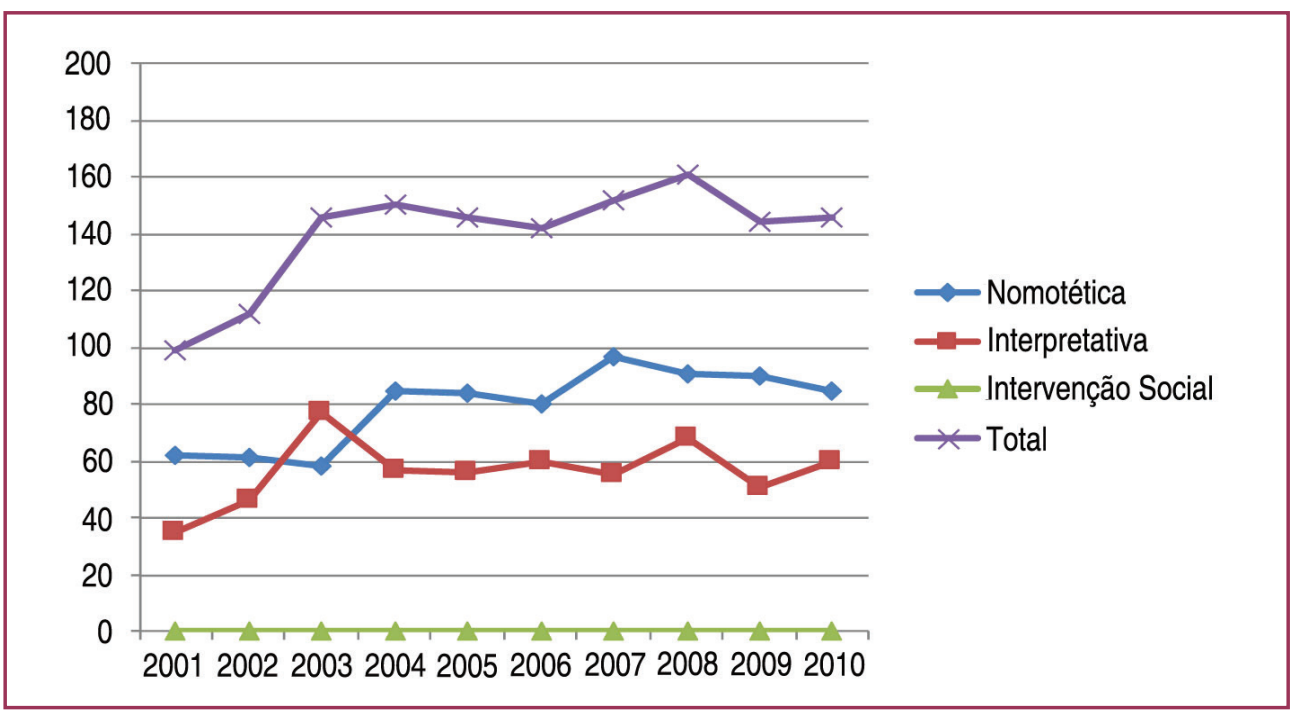

Fonte: dados originais da pesquisa.

Legenda: Evolução do número absoluto de dissertações e teses categorizadas em cada abordagem metodológica, no período de 2001 a 2010.

Esta vinculação a uma ou outra área do saber, expressa pela filiação metodológica dos trabalhos analisados, denota certo traço de dependência com relação a outras áreas do conhecimento. Com base em Bourdieu (1983a, 1983b, 1984, 2004), pode-se considerar a EF como um campo científico heterônomo. Nesse sentido, a dificuldade em constituir uma lógica própria - a construção de sua teoria autônoma - incorre em uma espécie de dependência de outros campos, ou seja, a disputa foge à lógica daquele campo (a EF), para uma outra que não a sua (outros campos, como a Educação, Saúde Coletiva, História ou afins) (LAZZAROTTI FILHO et al., 2012).

A área tem denotado um modelo polarizado em seu âmago de pesquisa e produção científica, em virtude de seu caráter plural no que tange a influências de outros campos. Mais do que opções metodológicas e de construção do objeto de estudo, o panorama aponta para uma perspectiva de EF fracionada (LAZZAROTTI FILHO et al., 2012).

Outro efeito causado pela heteronomia do campo é a forma de disputa pela configuração de sua estrutura. Bourdieu (1983a, 1983b, 1984, 2004) alerta que quanto mais heterônomo 0 campo científico, maior será o uso de estratégias ilícitas na tentativa de estruturá-lo de acordo com a vontade do grupo dominante de agentes/ pesquisadores. Isto é, utilizar meios que não os próprios da produção de conhecimento e conquista de prestígio pelos pares científicos como forma de pressão para moldá-lo à forma desejada (BOURDIEU, 2004).

Santos (2002) avança no sentido de compreender tal dicotomia como uma forma de expressar aquilo que a racionalidade tradicional dominante, no caso, a concepção dos pesquisadores que utilizam as abordagens metodológicas nomotética e interpretativa no campo científico da EF, julga importante ser central no debate. Neste caso, a disputa pelo domínio do campo entre estas duas vertentes metodológicas parece centralizar nas mesmas as possibilidades de pesquisa ditas "factíveis" no tempo presente, comprometendo assim, outras possibilidades.

Argumenta-se que essa polarização poderia obscurecer, então, outras formas de produção de conhecimento que extrapolem a lógica teórico-epistemológica das duas 
abordagens metodológicas mais expressivas, quantitativamente, encontradas nos resultados do presente estudo. Tal argumentação pode ser uma chave de resposta para a inexistência, conforme os critérios aplicados, de estudos de abordagem intervenção social, sustentando-se que não seja mero acaso. Por outro lado, pode ser resultado de disputas centradas apenas em concepções de pesquisas consideradas exequíveis pelos pesquisadores que atuam na conformação do campo científico da EF.

A análise apresenta perspectiva mais ampla ao utilizarmos os achados de Silva (1990, 1997) e Lüdorf (2002), que, utilizaram a categoria crítico-dialética em suas investigações. Silva (1990, 1997) deixa transparecer o vínculo destas abordagens com o Materialismo HistóricoDialético, o que poderia indicar, ao menos com bases nos achados do presente estudo, a perda de espaço deste referencial teórico dentro do campo da EF.

Para além da análise empreendida, é mister ressaltar que a distribuição de dissertações e teses vinculadas a uma ou outra abordagem metodológica não ocorreu de forma homogênea em todos os PPGEF. A figura 2 enfatiza a distinção entre as principais abordagens metodológicas, a partir de cada PPGEF.

Figura 2 - Abordagens metodológicas por PPGEF

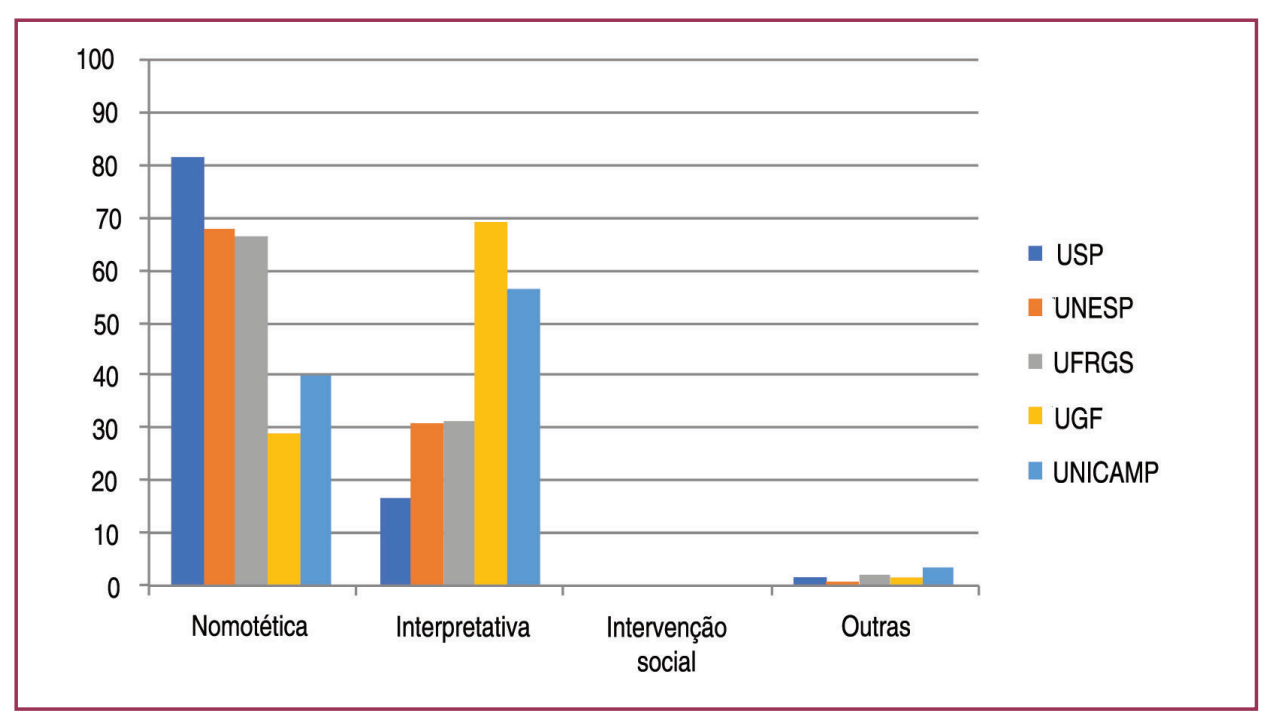

Fonte: Dados originais da pesquisa.

Legenda: Dissertações e teses nas diferentes abordagens metodológicas em cada PPGEF, no período de 2001 a 2010.

Os PPGEF UGF e UNICAMP destoam dos demais PPGEF em estudos anteriores, como Silva $(1990,1997)$ e Lüdorf (2002). As dissertações e teses são, predominantemente, vinculadas à abordagem metodológica próxima das Ciências Humanas e Sociais: a interpretativa.

Na perspectiva do campo científico da EF, os PPGEF USP, UNESP e UFRGS estão atrelados, em maior ou menor medida, à lógica de produção dominante e, consequentemente, à conservação do modus operandis vigente de produção na área. Já os PPGEF UGF e UNICAMP, situavam-se como foco de resistência no embate entre forças para conformação deste campo, na tentativa de moldá-lo, também, às suas disposições de produção científica, nos termos de Bourdieu (1983a, 1983b, 1984, 2004).

O cenário, entretanto, é agravado em razão do encerramento das atividades da UGF e de seu respectivo PPGEF no ano de 2014 (CASTRO et al., 2017, LÜDORF; CASTRO, 2017). 
Portanto, os resultados encontrados tendem à expressiva predominância de dissertações e teses cujo enfoque metodológico reside nas Ciências Naturais. Com o fechamento da referida universidade, perde-se também, o acervo de trabalhos outrora disponíveis na biblioteca digital da UGF. Assim, talvez este seja um dos raros estudos que tenham tido a oportunidade de lidar com esses dados, tão representativos para a EF brasileira.

É importante destacar a construção do campo científico da EF como local simbólico de lutas e tensões. Conforme Bourdieu (2004), o campo é um espaço de disputas políticas com objetivo de legitimar o que deve ou não ser pesquisado pelos agentes, ou ainda, o que deve e o que não deve valer como regra para a produção de conhecimento deste campo.

Bourdieu (1983a, 1983b, 1984, 2004) auxilia, então, na compreensão da configuração do campo científico da EF a partir dos embates entre agentes, ou seja, pesquisadores e entidades produtoras de conhecimento científico. Situamos, portanto, agentes que atuam no sentido da manutenção da estrutura deste campo científico - aqueles naturalmente vinculados à abordagem metodológica nomotética, por gozarem de hegemonia há mais de três décadas - e outros que visam sua transformação - agentes que lutam por espaço e pela transformação do campo, com objetivo de alterar as concepções de produção de conhecimento, na área.

Em outras palavras, há professores, pesquisadores e entidades em constante tensão para disputar verbas de pesquisa, regras que balizam a produção de conhecimento na área, bem como os formatos e veículos de divulgação científica, bolsas de auxílio financeiro à pesquisa, editais para compra de equipamentos e montagem de laboratório, dentre outros.

Neste contexto, a CAPES tem sido alvo de extenso debate acerca de sua gestão de políticas públicas que orientam os PPGEF. Desde a implementação de regras avaliativas da produção científica de PPGEF por parte desta instituição, na virada do século XX para o XXI, tem-se debatido intensivamente seus possíveis impactos na área (LOVISOLO, 2003; MANOEL; CARVALHO, 2011; MARCHLEWSKI; SILVA; SORIANO, 2011; LAZZAROTTI FILHO; SILVA; MASCARENHAS, 2014; SILVA; SORIANO, 2014).

Dentre outros aspectos, ressaltam-se algumas condutas adotadas pela CAPES, quanto à gestão científica no campo da EF, tais como: a ênfase na produção científica em formato de artigo; a pressão para publicação de artigos em periódicos internacionais; 0 baixo (ou nulo) valor atribuído a trabalhos publicados em anais de congressos e em formato de livros; a forma como os índices de qualificação de periódicos têm sido construídos; a valorização quantitativa - e não qualitativa - de citações de artigos; e, etc (CENÁRIOS ..., 2015).

Nesse sentido, autores como Manoel e Carvalho (2011) e Silva e Soriano (2014) têm demonstrado que estas normas incidem no campo de forma a privilegiar pesquisas cuja temática e abordagem metodológica encontram filiação teórico-epistemológica nas Ciências Naturais. Justificam-se ao afirmar, por exemplo, que possibilidades de publicação em periódicos internacionais são, em quase sua totalidade, voltadas às Ciências Naturais, induzindo, assim, um maior número de pesquisas que utilizem essa concepção de ciência. Atualmente, mesmo os periódicos nacionais têm passado por uma transição tendo em vistas à publicação em língua inglesa e consequente conformação a estas normas.

Além disso, com base na Carta de Porto Alegre (2018, p. 3), um dos impactos da forma de avaliação que impera na CAPES é a "asfixia lenta e gradual das subáreas sociocultural e 
pedagógica nos Programas de Pós-Graduação", com prejuízos ao próprio campo da EF em vista da ameaça aos seus pilares de sustentação. No contexto desta pesquisa, põe-se em risco as investigações vinculadas às concepções metodológicas interpretativa e de intervenção social.

Já Rigo, Ribeiro e Hallal (2012) verificaram que os PPGEF cujo corpo docente é constituído majoritariamente por pesquisadores próximos ao que consideramos no presente estudo como abordagem metodológica nomotética possuem conceitos maiores na avaliação CAPES. Atualizando-se esses dados, nota-se a manutenção dos conceitos ${ }^{7}$ mais altos dos PPGEF cujos resultados centraram-se na abordagem nomotética, como os PPGEF USP e UNESP, notas: 7 e 6, respectivamente. Em contrapartida, o PPGEF UNICAMP, programa que produz conhecimento majoritariamente atrelado à abordagem interpretativa, teve seu conceito reduzido de 5 para 4, dentro do período analisado.

Portanto, se por um lado o objetivo não é usar de uma visão maniqueísta, a qual pressupõe que os agentes no comando das instituições que estruturam a área, regem-na de acordo, apenas, com seus próprios interesses; é inegável as influências que os procedimentos que balizam as "regras do jogo" científico, na EF, têm orientado a produção de conhecimento da mesma (LAZZAROTTI FILHO; SILVA; MASCARENHAS, 2014; SILVA; SORIANO, 2014; RIGO; RIBEIRO; HALLAL, 2012)

A partir de Santos (2002), é preciso pensar numa lógica própria que surja como alternativa aos modelos dominantes no campo da produção de conhecimento ou em outros espaços sociais. O modelo de intervenção social, cuja característica elementar pressupunha ser uma alternativa aos paradigmas científicos hegemônicos, parece ter sido sequer considerado como possibilidade metodológica, reforçando os modelos da racionalidade tradicional que dominam a pesquisa na EF.

Para Bourdieu (1984), o poder sobre os mecanismos de reprodução repousa, dentre outros aspectos, no reforço prolongado das disposições reconhecidas pela ortodoxia acadêmica. $\mathrm{Na}$ esteira deste pensamento, é possível compreender o esvaziamento desta abordagem metodológica heterodoxa pela dificuldade de gerar, objetivamente, acúmulo e capital científico para o pesquisador do campo da EF. Nesse sentido, existe uma pressão interna para que os agentes produzam a partir de metodologias coerentes com a "regra do jogo válida" gerenciada pelas instituições que forjam as relações objetivas de produção no campo (SILVA; SORIANO, 2014). Como efeito, a Carta de Porto Alegre (2018, p. 3) explicita:

Se o percurso histórico da Educação Física levou à constituição de olhares diferentes para os mesmos objetos e processos, muitas vezes díspares: o biológico de um lado, o sociocultural de outro, hoje mais do que nunca é preciso colocá-los pari passu para proporcionar um Programa de Pós-Graduação que dê conta de formar estudantes com um olhar ampliado e repertório de ação diversificado para ir ao encontro do que a sociedade nos pede. Um Programa de Pós-Graduação em Educação Física que abdica de um desses olhares empobrece a qualidade da formação que oferece.

Desta maneira, corrobora-se o alerta de que a pós-graduação em EF, nesta toada, não esteja correspondendo à sua tarefa social de formar profissionais com olhar ampliado $\mathrm{e}$ repertório de ações diversificado (CARTA de PORTO ALEGRE, 2018).

7 Mais informações nas fichas de avaliação dos respectivos programas. Disponivel em: https://sucupira.capes.gov.br/sucupiral . Acesso em: 25 de fevereiro de 2018. 


\section{CONCLUSÕES}

Questões pertinentes à EF e seus nexos com a Ciência, pós-graduação e produção científica estão presentes no ethos da área, nos pilares de sua conformação no Brasil. Nos últimos anos, o debate em torno destas temáticas tem encontrado, no âmbito da pós-graduação, palco propício para estas discussões.

$O$ resultado geral, sobre as dissertações e teses analisadas, apontou para uma predominância da abordagem metodológica nomotética. Entretanto, nos PGGEF UGF e UNICAMP houve predominância da abordagem metodológica interpretativa. Já as produções derivadas dos PPGEF USP, UNESP e UFRGS se coadunaram com 0 resultado geral mencionado. Foi detectado, ainda, a não ocorrência de investigações que utilizassem a abordagem metodológica intervenção social.

Uma interpretação dos dados, a partir do diálogo com estudos anteriores e com a noção de "campo científico" de Pierre Bourdieu, revelou a consolidação de estruturas institucionais que têm direcionado a EF para a produção científica próxima à abordagem metodológica nomotética. A literatura revisada sugere que o controle das "regras do jogo", por parte de agentes vinculados a uma concepção metodológica de ciência atrelada às Ciências Naturais, têm gerado a manutenção da estrutura do campo científico da EF.

Importante destacar as limitações que um estudo, tal como o presente, possui ao tentar agrupar dissertações e teses de diferentes matizes e escopos metodológicos em três categorias temáticas. Se por um lado, tais agrupamentos podem criar certas amarras, por outro, permitem avançar na compreensão de uma visão mais ampla sobre o que e como se produz conhecimento científico em EF.

Finalmente, o presente trabalho levanta questionamentos para o direcionamento das políticas públicas de incentivo à pesquisa em EF, sobretudo em tempos de cortes para 0 financiamento científico no país. Em se tratando de uma área caracterizada pela sua diversidade epistemológica, é urgente avançar na agenda de discussão em que seja possível estabelecer procedimentos avaliativos que contemplem todas as suas vertentes.

\section{REFERÊNCIAS}

BETTI, Mauro; CARVALHO, Yara Maria de; DAOLIO, Jocimar; PIRES, Giovani De Lorenzi. A avaliação da educação física em debate: implicações para subárea pedagógica e sociocultural.

Revista Brasileira de Pós-Graduação, v. 1, n. 2, p. 183-194, nov. 2004.

BOURDIEU, Pierre. O campo científico. In: ORTIZ, Renato. (org.). Pierre Bourdieu -

Sociologia. São Paulo: Ática, 1983a. Coleção Grandes Cientistas Sociais. p. 122-156.

BOURDIEU, Pierre. Questões de sociologia. Rio de Janeiro: Marco Zero, 1983b.

BOURDIEU, Pierre. Homo academicus. Paris: Les éditions de Minuit, 1984.

BOURDIEU, Pierre. Os usos sociais da ciência: por uma sociologia clínica do campo científico. São Paulo: UNESP, 2004. 
BOURDIEU, Pierre. 0 poder simbólico. 15. ed. Rio de Janeiro: Bertrand Brasil, 2011.

CASTRO, Pedro Henrique Zubchich Caiado de; SILVA, Alan Camargo. IMBIRIBA, Luis Aureliano; LÜDORF, Sílvia Maria Agatti. A produção científica em Educação Física de 2001 a 2010: caminhos da construção de um campo. Movimento, , v.23, n.3, p.869-882, 2017.

CARTA DE PORTO ALEGRE. In: FÓRUM DE PÓS-GRADUAÇÃO DO COLÉGIO BRASILEIRO DE CIÊNCIAS DO ESPORTE, 8. ; FÓRUM DE PESQUISADORES DAS SUBÁREAS SOCIOCULTURAL E PEDAGÓGICA DA EDUCAÇÃO FÍSICA, 5. Anais [...], 2018. Disponível em: http://www.cbce.org.br/upload/biblioteca/carta forum porto alegre 2018.pdf. Acesso em: 29 jan. 2019.

CENÁRIOS de um descompasso da pós-graduação em Educação Física e demandas encaminhas à CAPES. In: FÓRUM DOS PESQUISADORES DAS SUBÁREAS SOCIOCULTURAL E PEDAGÓGICA, Anais [...], 2015. Disponível em: http://www.cbce.org.br/ noticias-detalhe.php?id=1074. Acesso em: 10 jan. 2019.

CONCEIÇÃO, Paulo Felix Marcelino. "Amarelão" no esporte: das alterações da cor da pele ao coping do estresse por crenças religiosas e lócus do controle de atletas de handebol, ginástica artística e voleibol. 2009. 176 f. Tese (Doutorado em Biodinâmica do Movimento Humano) Escola de Educação Física e Esporte, Universidade de São Paulo, São Paulo, 2009.

DACOSTA, Lamartine Pereira; DUARTE, Cátia Pereira. O debate epistemológico da Educação Física no âmbito dos cursos de pós-graduação stricto sensu reinterpretado por contribuições da Teoria da Complexidade de Morin. Revista Brasileira de Ciências do Esporte, v. 24, n. 2, p. 147159, jul. 2003.

GAYA, Adroaldo (org.). Ciências do movimento humano: introdução à metodologia da pesquisa. Porto Alegre: Artmed; 2008.

GOMES, Ricardo José. Treinamento físico aeróbio e o eixo de crescimento GH/IGF-1 em ratos diabéticos experimentais. 2005. 67f. Tese (Doutorado) - Instituto de Biociências de Rio Claro, Universidade Estadual Paulista, Rio Claro, 2005.

KOKUBUN, Eduardo. A avaliação da Educação Física em debate: esclarecimentos. Revista Brasileira de Pós-Graduação, v. 1, n. 2, p. 195-200, nov. 2004.

KOKUBUN, Eduardo. Pós-graduação em educação física no Brasil: indicadores objetivos dos desafios e das perspectivas. Revista Brasileira de Ciências do Esporte, v. 24, n. 2, p. 9-26, jan. 2003.

LAZZAROTTI FILHO, Ari; SILVA, Ana Marcia; NASCIMENTO, Juarez Vieira do; MASCARENHAS, Fernando. Modus operandi da produção científica da Educação Física: uma análise a partir das revistas e suas veiculações. Revista da Educação Física/UEM, v. 23, n. 1, p. 1-14, 1. trim. 2012.

LAZZAROTTI FILHO, Ari; SILVA, Ana Marcia; MASCARENHAS, Fernando. Transformações contemporâneas do campo acadêmico-científico da Educação Física no Brasil: novo habitus, modus operandi e objetos de disputa. Movimento, v. 20, n. esp., p. 67-80, 2014.

LOVISOLO, Hugo Rodolfo. A política de pesquisa e a mediocridade possível. Revista Brasileira de Ciências do Esporte, v. 24, n. 2, p. 97-114, jul. 2003.

LÜDORF, Sílvia Maria Agatti. Panorama da pesquisa em Educação Física da década de 90: análise dos resumos de dissertações e teses. Revista da Educação Física/UEM, , v. 13, n.2, p. 19-25, 2002. 
LÜDORF, Sílvia Maria Agatti; CASTRO, Pedro Henrique Zubcich Caiado de. Realidades da pós-graduação em educação física: manutenção ou desmonte das subáreas sociocultural e pedagógica? In: TELLES, Silvio; LÜDORF, Sílvia Maria Agatti; PEREIRA, Erik Giuseppe. Pesquisa em educação física: perspectivas sociocultural e pedagógica em foco. Rio de Janeiro: Autografia, 2017. p. 21-34.

MACHADO, Raoni Perrucci Toledo. Esporte e religião no imaginário da Grécia Antiga. 2006. 105f. Dissertação (Mestrado em Pedagogia do Movimento Humano) - Escola de Educação Física e Esporte, Universidade São Paulo, São Paulo; 2006

MANOEL, Edilson de Jesus; CARVALHO, Yara Maria. Pós-graduação na educação física brasileira: a atração (fatal) para a biodinâmica. Educação e Pesquisa, v.37, n.2, p. 389-406, maio/ ago. 2011.

MARCHLEWSKI, Camila; SILVA, Priscilla Maia da; SORIANO, Jeane Barcelos. A influência do sistema de avaliação Qualis na produção de conhecimento científico: algumas reflexões sobre a Educação Física. Motriz, v.17 n.1, p.104-116, jan./mar. 2011.

MINAYO, Maria Cecília de Souza. 0 desafio do conhecimento: Pesquisa qualitativa em saúde. 3. ed. São Paulo-Rio de Janeiro: Hucitec-Abrasco, 1994.

OLIVEIRA, Rogério Cruz. Na "periferia" da quadra: educação física, cultura e sociabilidade na escola. 2010. 134f. Tese. (Doutorado em Educação Física) - Faculdade de Educação Física, Universidade Estadual de Campinas, Campinas, 2010.

RIGO, Luis Carlos; RIBEIRO, Gabriela M.; HALLAL, Pedro C. Unidade na diversidade: desafios para a Educação Física do Século XXI. Revista Brasileira de Atividade Física \& Saúde, v. 16, n. 4, p. $339-345,2012$.

ROSA, Suely; LETA, Jacqueline. Tendências atuais da pesquisa brasileira em Educação Física Parte 2: a heterogeneidade epistemológica nos programas de pós-graduação. Revista Brasileira de Educação Física e Esportes, v.25, n.1, p.7-18, jan./mar. 2011.

SANTOS, Boaventura de Sousa. Para uma sociologia das ausências e uma sociologia das emergências. Revista crítica de ciências sociais, n. 63, p. 237-280, 2002.

SILVA, Priscilla Maia da; SORIANO, Jeane Barcelos. Qualis periódicos e a produção de capital científico nos programas de pós-graduação em Educação Física. Movimento, v. 20, n. 1, p. 281304, jan/mar. 2014.

SOUZA E SILVA, Rossana Valéria. Mestrados em Educação Física no Brasil: Pesquisando suas pesquisas. 1990. 124f. Dissertação. (Mestrado em Ciência do Movimento Humano - Universidade Federal de Santa Maria, Santa Maria, 1990.

SOUZA E SILVA, Rossana Valéria. Pesquisa em Educação Física: determinações e implicações epistemológicas. 1997. 291f. Tese (Doutorado em Educação) - Campinas: Universidade Estadual de Campinas, 1997.

TURATO, Egberto Ribeiro. Tratado da metodologia da pesquisa clínico-qualitativa: construção teórico-epistemológica, discussão comparada e aplicação nas áreas da saúde e humanas. 2.ed. Petrópolis, RJ: Vozes, 2003.

VANNI, Adriane Carla. Comparação de dois modelos de treinamento de força na densidade mineral óssea, força muscular, antropometria e lesão muscular em mulheres pré- 
menopáusicas. 2008. 140f. Dissertação (Mestrado em Ciências do Movimento Humano) Escola de Educação Física, Universidade Federal do Rio Grande do Sul, Porto Alegre, 2008. 